\title{
Chapter 10 \\ Discourses on Nanotechnology \\ in Europe, China and India
}

\author{
Camilo Fautz, Torsten Fleischer, Ying Ma, Miao Liao and Amit Kumar
}

\subsection{Introduction}

For roughly 15 years, 'nanotechnology' has been established as a generic term for a wide and inhomogeneous field of science and technology branches that enable us to manipulate, observe and measure at a scale of less than $100 \mathrm{~nm}$. One nanometre is equal to one billionth of a metre. Nanotechnology or, more precisely, nanotechnologies as the application of nanoscience - an interdisciplinary science that cuts across established scientific and engineering disciplines like chemistry, physics, biology, or engineering - consists of overlapping technologies in which different

C. Fautz $(\square) \cdot$ T. Fleischer

Institute for Technology Assessment and Systems Analysis (ITAS),

Postfach 3640, 76021 Karlsruhe, Germany

e-mail: camilo.fautz@kit.edu

T. Fleischer

e-mail: torsten.fleischer@kit.edu

Y. Ma

Chinese Academy of Science and Technology for Development (CASTED),

8 Yuyuantan South Road, Haidian District 100038, Beijing, China

e-mail: may@casted.org.cn

M. Liao

Center of Science, Technology and Society, Tsinghua University, Beijing,

People's Republic of China

e-mail: melian@yeah.net

A. Kumar

RIS, Zone IV-B, Fourth Floor, India Habitat Centre, Lodhi Road,

New Delhi 110003, India

e-mail: amit.kumar@ ris.org.in 
industrial sectors such as communication, health care and biotechnology meet and partly converge. Moreover, because it provides a toolkit for realizing certain (pre-) products in many sectors, nanotechnology has been classified as an 'enabling technology' and as a starting point or exemplar of a new industrial revolution. The broad and open definition of the umbrella term 'nanotechnology', as well as comprehensive visions and expected research and development programmes, have led to the creation or designation of new subdisciplines (or 'hyphen disciplines') such as nano-electronics, nano-medicine, nano-ethics and nano-toxicology.

At the nanoscale the characteristics of matter can be significantly altered because of size-specific properties such as the dominance of quantum effects: for example, downsized material structures that consist of the same chemical elements may change their mechanical, magnetic, electronic and optical properties. Engineered nanomaterials ${ }^{1}$ are manufactured for specific ends, such as carbon nanotubes for reinforced car tyres or antistatic packaging, nanosilver particles for antibacterial coatings, titanium carbide for harder cutting tools and nanoparticles for drug delivery. Nanomaterials appear in different forms and are generally categorized according to their dimensions: for instance, very thin surface coatings, films or layers are nanoscale in one dimension; nanotubes, nanowires and fibres are nanoscale in two dimensions; nanoparticles, quantum dots and nanoshells are nanoscale in three dimensions.

During the 1990s some governments set up state-run promotional programmes for nanotechnology, although they did not then use the actual term 'nanotechnology' (Wullweber 2010: 157). At the end of the 1990s nanotechnology became a positive guiding vision (Leitbild $)^{2}$ for future technology development. Science policy and governmental actors succeeded in shaping a programmatic nano-discourse by linking far-reaching promising nano-visions to the current state of the art in specific fields of nanotechnology, such as nanomaterials and nanoelectronics. The fields identified for governmental action were taken up in governmental nanotechnology research and development programmes introducing mid-term guiding visions for the shaping of the nanotechnology discourse in particular and the science and technology policy discourse in general. Important technology policy actors from leading industrial countries started framing the field of nanotechnology by conceptualizing different developments under the umbrella term 'nanotechnology', through research and development programmes showing the medium- and long-term way forward, and by establishing and maintaining networks embracing actors in research, industry, politics and the public sphere. 'Nanotechnology has arguably been the strongest movement in the re-organization of the disciplinary landscape of science and engineering worldwide in the past decade' (Schummer 2007: 670, 671).

\footnotetext{
${ }^{1}$ Besides engineered or manufactured nanomaterials, there are also natural nanomaterials like volcanic ash, fire smoke, clay and evaporating sea salt.

${ }^{2}$ Leitbilder (guiding visions) are close to being concrete technological developments, but have not yet been realized, though there is good evidence of their feasibility (Grunwald 2005).
} 
The first and biggest nanotechnology research and development programme explicitly promoting nanotechnology, the National Nanotechnology Initiative, was initiated by the US government in 2000:

Nanotechnology is the first economically important revolution in science and technology (S\&T) since World War II that the United States has not entered with a commanding lead. Federal and industrial support of R\&D in the United States for this field already is significant, but Europe and Japan are each making greater investments than the United States is, generally in carefully focused programs. Now is the time to act (National Science and Technology Council 2000: 114).

From 2000 to 2007 more than 60 countries established more or less comprehensive and coherent nanotechnology research and development programmes (Roco 2007: 37). This worldwide nanotechnology-oriented innovation process is situated in a highly competitive field among leading industrial nations and regions. Governments and actors in the science industry in particular are encouraging a robust innovation discourse that characterizes nanotechnology as a revolutionary key technology, highlighting its potential benefits and possible contribution to big societal challenges, such as global competitiveness and sustainability, and aims, such as economic growth and the wellbeing of the population. In the field of energy production, for example, semiconductor nanowires and quantum dots have potential for sustainable solar energy harvesting. Promising applications in the field of medicine are personalized drug delivery and the in situ regeneration of bones.

Some actors, on the other hand, including researchers in science and technology studies and non-governmental organizations (NGOs), contrast the potential benefits with uncertainties and possible environmental, health, and safety risks as a counterbalance to this innovation paradigm, since not much is known about the interaction of nanomaterials with the human body or the environment. Besides these primary or absolute risks there are also secondary or related socioeconomic risks involving autonomy and democratic codetermination or global justice and societal equity through an entrenchment of current market and political power imbalances (the nano-divide). In particular, the discussion on governance and the risk assessment of nanotechnologies has led to an entanglement of different argumentation patterns, principles and value concepts.

Nanotechnology encompasses a wide and heterogeneous field of technologies and possible applications, including far-reaching visions of converging technologies, human enhancement and transhumanism. Here we apply a more down-toearth approach to nanotechnologies, focusing on nanomaterials.

\subsection{Discourses on Innovation, Risk, and Power and Control}

Since we are comparing discourses on nanotechnologies in Europe, China and India - three different regions with different sociocultural histories and socioeconomic contexts- the term 'discourse' is to be understood in quite a broad sense. 
Our analysis ${ }^{3}$ will show how the umbrella term 'nanotechnology' is conceptualized by one or more actors in each of the three regions, as well as how this conceptualization refers to region-specific sociocultural value conceptions.

\subsubsection{Innovation}

As stated in the introduction, nanotechnology has become a worldwide exemplar of industrial progress and innovation. Actors in science policy and the science industry link the development of nanotechnology to a wide range of beneficial applications. In each region, those involved in any innovation discourse have to show how their conceptualization of nanotechnology fits societal needs in order to represent nanotechnology as a socially robust sociotechnical system.

All three regions have been involved in research at the nanoscale since the 1980s, with awareness of nanomaterials growing during the 1990s. The nanotechnology innovation discourse also started in all three at about the same time, the beginning of the 2000s. But there are significant differences between the regions in innovation policy. Whereas China and many EU member states set up guiding and envisioning nano-strategies and permanent central coordinating bodies, India started by launching a Nano Science and Technology Initiative coordinated by the Department of Science and Technology, which also oversees other science and technology activities.

\subsubsection{European Union}

The development of a coherent policy for nanotechnologies at a European level can be traced back to the year 2000, when the cross-departmental Unit G4: Nanosciences and Nanotechnologies was established in the European Commission's Directorate-General for Research, in order to gather information from other directorates-general and services with the aim of providing guidance for the European nanotechnology strategy and distributing research funds for nanotechnologies from the EU's multi-annual Framework Programmes for Research and Technological Development. Although nano-specific promotion programmes did not exist before the year 2000, there were some early efforts at nanotechnology research and development in the fourth and fifth framework programmes of the European Commission.

In May 2004 the commission adopted the communication 'Towards a European strategy for nanotechnology' (European Commission 2004), followed by an action plan for nanosciences and nanotechnologies in 2005 (European Commission 2005). In these policy papers the commission refers to the potential contribution of nanosciences and nanotechnology to addressing many of today's societal challenges, especially in medicine, information technologies, food and water, energy and

3 This analysis is mainly based on Fautz et al. 2014. 
environment, as well as security. It notes the strong knowledge base in nanosciences that the EU has established over the preceding decade, but doubts that the EU is in a good position relative to its main international competitors, since it is investing less and lacks world-class infrastructure. The commission makes the point that European excellence has to be translated into commercially viable products within a favourable environment for innovation. At the same time it addresses environmental, health and safety (EHS) aspects and ethical, legal and social implications, confirming that nanotechnologies must be developed in a safe and responsible manner.

The EU and its member states have continued to foster nanotechnologies by issuing action plans and research strategies with international engagement and by supporting or releasing codes of conduct for research and development.

So, for Europe, we can observe a broad governmental policy engagement to develop a coherent strategy on nanotechnology including a variety of actors, particularly in science and industry. Critical voices make references to prior discourses, developments and governance failures in the field of new and emerging technologies, such as biotechnologies, but governments too have learned from prior conflicts and developed more sophisticated strategies of anticipatory governance and conflict reduction, including certain forms of dialogue and participation.

The main innovation narrative is that of nanotechnologies exercising a kind of collective beneficence for society as a whole. Government policy papers raise expectations and emphasize how nanotechnologies can potentially benefit all citizens and the environment by addressing grand societal challenges-like fighting diseases, improving food and water safety, making the production and use of energy more efficient, protecting the environment, enhancing the security of human life and private property and increasing the economic wealth of the whole of society-in accordance with basic principles such as justice, autonomy and sustainability. In this way the main drivers of the innovation discourse directly or indirectly invoke the European values of equality, freedom and solidarity: equality of chances for wellbeing through economic growth; freedom of research as well as to conduct business; and solidarity by improving the health situation of the people and the environment through nanotechnologies.

\subsubsection{China}

In China, the main driver of the innovation discourse is the government. This is welcomed by industry, but also overwhelmingly by researchers, social scientists and the public, who all largely share a common vision and conception of national progress. In March 2001, the Chinese government established the National Committee for Direction and Coordination of Nanoscience and Nanotechnology Research to allow the comprehensive and coherent planning of such research across the country and to coordinate the actions of the various players. In July 2001, the National Programme on the Development of Nanoscience and Nanotechnology (MOST 2001) was released to provide specific planning for the overall development of nanotechnologies. In 2006, the State Council of 
the People's Republic of China released the Outline of National Medium- and Long-Term Science and Technology Development Plan (MOST 2006), in which nanoscience was described as 'one of the most promising areas where leap-frog development is possible' since nanotechnologies had the potential to 'give birth to a new technology revolution, and create huge development space for materials, information, green manufacturing, biology, and medicine in China' [our translation]. In 2012, a special five-year nano research plan (MOST 2012a) was formulated in order to deepen the implementation of the outline plan (MOST 2006) and advance major national scientific research programmes.

Although a handful of big national companies, such as Haier, are involved in nanotechnologies research, most industrial investments come from new business actors, in contrast to what is happening in other countries, where the majority of investors are big companies (Ren and Zhang 2010). Moreover, the nano industry field is subject to the economic need and political will for high increases in gross domestic product, making local governments eager for earlier returns on investment (Zhou 2007). This impatience has led to the low level of industrialization of nanotechnologies in China.

In terms of values, both progress and affluence can be identified as important reference points for the Chinese innovation discourse. The value of progress is embedded in the widely shared concept of social evolutionism. This is evident in the government's praise of economic progress through innovation aimed at catching up in international market competition and making the Chinese nation a self-reliant global leader in science, technology, and innovation. The scientific community supports these aims, with a particular focus on promoting research in order to perform well in international science and technology competition. Chinese enterprises that jump on the nano-train expect improved products for international competition, and can benefit from the public's appreciation of technological applications that symbolize societal progressiveness and individual wealth. Therefore affluence is the other main value of the government's innovation discourse, with the Communist Party deriving its legitimacy from its ability to guide the Chinese people to an affluent life through the improvement of their livelihood and the creation of material wealth. Closely related to this are the values of personal wellbeing and of social and ecological harmony.

\subsubsection{India}

In India, the main focus area of nanotechnology for government and industry lies in addressing urgent societal needs and challenges, as well as in the competitive commercialization of nano-enabled consumer products. The Department of Science and Technology launched the Programme on Nanomaterials: Science and Devices in 2000 in order to initiate some end-to-end projects leading to tangible technologies, processes and technologies. The emphasis was on projects addressing urgent national challenges like water purification, alternative energy production and conservation (DST 2001). An expert group on Nanomaterials: Science and Devices, charged with the development of a National Nanoscience and Nanotechnology Initiative, was launched in October 2001 under the aegis 
of the department. The key targets of the initiative were to create research infrastructure and to promote basic research in nanoscience and nanotechnology. It focused on various issues relating to infrastructure development, basic research and application-oriented programmes in nanomaterial, including drugs, drug delivery, gene targeting and DNA chips. Nanotechnology was heralded as a revolutionary technology with applications in almost every aspect of life. In recognition of the important role and multifaceted applications of nanotechnologies, the initiative was elevated to the level of a mission programme in 2007 (called the Nano Mission), with enhanced funding from the government. Primary objectives of the Nano Mission are basic research promotion, infrastructure development, the creation of public-private partnerships and technology development centres, human resource development, and international collaboration (DST 2008).

In terms of values and principles, the innovation discourse in India is mainly driven by the principle of beneficence-that is, doing good for others, here referring to society and the nation. This means that nanotechnological innovation is seen as bringing society wellbeing and justice in terms of access, equity and inclusion, since nanotechnologies are expected to address major social challenges and to push economic growth.

\subsubsection{Risk}

One of the challenges in nanotechnology policy, and in related ethics discourses, is the heterogeneity of the field, something that has become particularly obvious in the case of risk discourses. In early stages, these dealt with various nanotechnology approaches and applications, but since the mid-2000s, they have focused on the EHS risks of nanomaterials. For our comparison of risk discourses, important questions are:

- What kinds of risks are linked to nanotechnologies?

- How are they dealt with?

- How are they balanced against expected benefits?

EHS risk issues appeared almost at the same time in Chinese and European research communities. The Chinese government integrated risk research into its policy agenda - in particular thanks to advocacy and promotion by scientists-on the basis of a cost-benefit framework. In India, a risk management framework still has to be developed.

\subsubsection{European Union}

Within its Fifth Framework Programme for Research and Technological Development (1998-2002), the EU started funding specific research on EHS aspects of nanotechnologies (Aguar and Murcia Nicolas 2008). Since the years 2003 
and 2004, EHS issues have increasingly been addressed by a variety of actors in Europe-including NGOs, the European Parliament, regulatory authorities, expert bodies, reinsurance companies and those involved in science and technology studies - and the risk (governance) discourse has become one of the strongest and most visible discourses in the debate on nanotechnologies, creating linkages with other nano-discourses and scrutinizing conventional risk assessment frameworks with reference to the precautionary principle or sustainability. By the year 2004, the first expert recommendations initiated by the European Commission appeared (e.g. Malsch 2004), emphasizing the need to assign new Chemical Abstracts Service (CAS) registry numbers to manufactured nanoparticles and to classify them in categories of risk, toxicity and proliferation. This has since been elaborated in the emerging subdiscipline of nanotoxicology (Kurath and Maasen 2006), where new risk assessment methods are being developed for the new and unknown properties of nanomaterials. Also reinsurance companies, by applying consequentialist risk assessment frameworks, soon became aware of possible EHS risks and emphasized the need for increasing risk research funds (Hett 2004; Lauterwasser 2005).

Even though there are no separate regulatory frameworks for nanotechnologies, the current EU regulations provide the most important framework for the activities of EU member states in this field. Moreover, in October 2011, the European Commission adopted a recommendation on the definition of the term 'nanomaterial', which was criticized by environmental, health and animal protection NGOs (CIEL et al. 2011) for being too narrow in scope and hence not adequate to deal with the risks of nanomaterials outside the range of 1-100 nm.

The European Parliament, the European Commission and several authoritative European and national research bodies commissioned by the European Commission and member state governments discussed and analysed the appropriateness of risk management frameworks in current legislation for handling nanorelated risks, and the commission addressed EHS issues in many statements and funded research projects. But on concrete risk assessment and management measures, differences in risk perceptions became obvious between the more proactionary commission and industry on one side and the more precautionary European Parliament and civil society stakeholders on the other. Scientific expert bodies generally recommended a case-by-case approach to risk assessment and sometimes expressed doubts about the fitness of relevant legislation for nanoscale materials, in the absence of sufficient data on the behaviour of nanomaterials in the human body and the environment.

As a counterbalance to the Promethean innovation rationale, the main advocates of an alternative European risk discourse base their argumentation mainly on the principles of non-maleficence, justice and precaution. They reject consequentialist or utilitarian standard risk frameworks as falling short of the challenges entailed in given scientific uncertainties and call for new and enhanced measures for the evaluation of and protection from EHS risks and physical harm, referring to principles such as sustainability and precaution. A good example is the risk and regulation discourse centred on European chemicals regulation, as outlined in the report Ethics Debates on Nanotechnologies in the EU (Fautz 2013). Moreover, there is 
ongoing discussion among those engaged in science and technology studies, as well as between NGOs and governments, on risk assessment procedures as such: whether they can still be based on classical and mainly consequentialist frameworks or should rely on specific interpretations of the precautionary principle.

The values invoked in this discourse are mainly solidarity, human dignity and equality: solidarity in terms of protecting human and environmental health, for instance by insisting on high regulatory standards for the use and release of nanomaterials; human dignity and equality in terms of individual physical integrity, in that no-one should be exposed to risks against his/her own will or for the profit of others, even if utilitarian positions would justify exposing some people to higher risks for the sake of majority welfare.

\subsubsection{China}

Nanotoxicology research has become an important field for Chinese researchers to raise their profile as international high-level scientists. Moreover, the nano-scientists can be seen as the dominant actors in the Chinese risk discourse on nanotechnologies. It is particularly thanks to the advocacy and promotion of the scientists that the government included the topic of nanosafety in its policy documents and earmarked funds for the research of EHS aspects.

The Chinese State Guidelines on Nanotechnology Development released in 2001 did not mention risk research and management. Nevertheless, China's science community paid attention to the safety of nanotechnologies quite early. In November 2001, a group of chief scientists on nanotechnologies proposed conducting research on the bio-effects, toxicity and safety of nanotechnologies (Zhao and Chai 2005). In 2003, the Chinese Academy of Sciences set up an open lab on nano bio-effects and nano safety, which later became the Key Laboratory for Biomedical Effects of Nanomaterials and Nanosafety. Since its establishment, the lab has made important contributions to nanotoxicology. In addition, the Chinese research community has held several symposiums since 2004 on the safety of nanotechnologies.

In 2005, the Chinese government started formulating standards to regulate nano-related research, production and application and to control possible risks and harm (Shen and Wang 2011). The nanotechnology health, safety and environment standardization group was established in March 2010 to take responsibility for standardization in relation to the EHS impacts of nanomaterials and products during their manufacture, packing, transportation and use. In 2011, a standards research project, Health and Safety of Nanotechnology in Workplace, was set up. In the 12th Five-Year Special Plan for Major National Scientific Research Program on Nano Research, from 2012, efforts were announced to 'pay attention to standardized manufacture of nanotechnology products and formulate several product standards and safe production rules for important nanotechnology products'. In addition, 'nanotechnology safety' was listed as one of the nine major research tasks (MOST 2012b). But still there are no regulatory policy measures apart from international attempts at standardization. 
Discussions of health and environment issues in the risk discourse are related to the values of safety and harmony. But all participants in that discourse link safety and harmony directly to progress and innovation by emphasizing the importance of reducing the occurrence of hazardous or anomalous situations that could threaten progress and affluence. The relatively uncontroversial framing of the risk discourse among those involved might also be based on the fact that currently applied conventional risk assessment frameworks of cost-benefit analysis, which acknowledge only proven risks, remain largely uncontested.

\subsubsection{India}

In India, risk assessment of nanotechnologies does not rank as high on the policy agenda as in China or Europe. Some actors have tried to push this issue, but so far there has not been much significant research or policy action. There are a few Indian authors who follow international risk research and debates (e.g. Seetharam and Sridhar 2007; Srinivasan 2008), trying to get these issues higher up the Indian policy agenda or, at least, to promote them in the Indian research community and raise awareness (e.g. Pradeep and Burgi 2006). Dhawan and Sharma (2011) criticized the fact that among more than 200 funded projects of the Indian Nano Mission programme from 2001 to 2010, only one could be directly related to nanotoxicity studies. The International Conference on Nanomaterial Toxicology (ICONTOX), jointly organized by the Indian Institute of Toxicology Research and the Indian Nanoscience Society in 2008, was a rare exception.

In 2010 the government appointed a 'Task Force for developing Regulatory Framework on Nanotechnology' and announced that a nanotechnology regulatory board would be set up, but so far not much has happened. The Department of Science and Technology and other agencies have meanwhile sponsored some research on EHS aspects of nanotechnologies, but the outcome of that research and its policy impact remain unclear. Risk governance of nanomaterials is an important subject of research and negotiation in various international arenas, including the Organisation for Economic Co-operation and Development and the United Nations Educational, Scientific and Cultural Organization. But so far, there has not been much significant research or policy action in India.

In terms of invoked values, the few critical voices that are trying to develop a risk discourse argue in favour of protecting the health of all potentially affected individuals as well as the environment. This concept corresponds with the Indian value of fraternity, which refers to the dignity of the person.

\subsubsection{Power and Control}

The power and control discourse deals with issues of political and economic power and justice. It is about whose interests are served by nanotechnology development 
policies and regulations, about who has to take the risks and who can profit from its benefits. These are very sensitive issues, since stakeholders in the nanotechnology field may have conflicting interests concerning the use and framing of nanotechnologies.

\subsubsection{European Union}

Like the risk discourse on nanomaterials, the power and control discourse in Europe emerged around the years 2003 and 2004, when current nanotechnology developments underwent their first technology assessment studies. With a strong innovation discourse making nanotechnology an exemplar of technologically driven innovation, the question of an adequate and inclusive governance framework consequently became a hot topic among actors in the field of nanotechnology discourse. The leading figures in the power and control discourse are philosophers, writers on science and technology studies, and NGOs that are keeping a critical eye on the high expectations that accompany the development of nanotechnologies. They are tackling issues of controllability and power, or of access and equity, and advocate the inclusion of broader socioeconomic impacts, such as the consequences for developing countries, in governance frameworks for nanotechnologies. In doing so they also refer to similar developments in other fields of technology, for instance biotechnologies. Furthermore, the power and control discourse overlaps broadly with the risk discourse, where the Promethean positions of governments and industry, focusing on opportunities for innovation and competitiveness, are opposed by the precautionary world views and inclinations of NGOs, the European Parliament and the general public.

In 2006 NGOs began to contribute substantially to the social debate on nanotechnologies in Europe. Most NGOs focused on threats to health and the environment posed by nanomaterials, issues of controllability and power, and questions of access and equity. After initial calls for a moratorium on the use of nanomaterials in consumer products, civil society organizations and trade unions developed quite distinct positions on nanotechnologies. On the one hand they acknowledged the beneficial potential of nanosciences and nanotechnology for society, the environment and the economy, and shared expectations raised by governments. On the other hand they were concerned because the risks of manufactured nanoparticles were not being fully assessed, and they favoured stricter precautionary legal frameworks to protect consumers, workers and the ecosystem. Important issues of the European power and control discourse were labelling, privacy and security, regulatory issues, risk-benefit distribution and the nano-divide, research funding for EHS aspects, public funding as against private funding, and market power.

In order to promote and demonstrate the responsible development of nanotechnologies, governments, regulatory bodies and industry set up-more or less successfully_voluntary reporting schemes, risk management frameworks and codes of conduct, measures that can be seen as experimental approaches to dealing with the uncertainties and challenges in the dynamic field of nanotechnologies. On 7 
February 2008, the European Commission recommended the adoption of a code of conduct for responsible nanosciences and nanotechnology research, which had been developed during an open consultation phase. The code combines a number of general EU policy objectives, such as competitiveness, precaution, sustainability and public consultation, with the aim of ensuring integrated, safe and responsible nanosciences and nanotechnologies research for the benefit of the society as a whole (European Commission 2008). A survey in 2011 showed, however, that while respondents generally agreed with the code, only $15 \%$ said that their organizations had adopted it.

In terms of principles and values, the most proactive participants in the European power and control discourse-philosophers, authors on science and technology studies, and NGOs - are expanding the risk discourse, which is mainly centred on scientific evidences and paradigms, by emphasizing the socioeconomic and sociocultural dimensions of nanotechnology. Within this broader framework the potential benefits of nanotechnologies are balanced not only against possible EHS risks and principles such as non-maleficence and sustainability, but also against possible socioeconomic risks and principles like autonomy or justice. Here the concept of autonomy-which is a core element of all modern Western theories of democracy_refers to the European values of freedom, solidarity, equality and human dignity, and to principles such as citizens' rights, justice, sustainability and precaution, which guarantee citizens a life free of coercion and make them coauthors of their common life contexts within their political communities. Dignity is addressed in terms of the individual integrity and individual rights of a person; freedom in terms of the person's right to liberty, security and information, as well as respect for and protection of privacy and personal data; and solidarity and equality in terms of social security, access to basic goods and services, and societal inclusion.

\subsubsection{China}

In China, generally speaking, the power and control discourse is overshadowed by the government's innovation discourse and the widely shared aim of rapid progress for China among actors in the science and technology field.

Concerning questions related to this discourse, Chinese participants in the nanotechnology field remain quite reserved or cautious. Some calls for a moratorium on nanotechnologies in China have been brought into the discussion via international NGOs. When reporting on these debates, the media have basically maintained a neutral stance, but a few reports have called attention to the right of the public to know and urged government administrations to take note of public attitudes and consider mechanisms for government supervision and policy adjustment.

The government's attitude to power and control issues is primarily focused on bolstering the country's independence of external influences, particularly by ensuring that it attains a leading position in international military and economic 
competition. This perspective, which relates the value of progress to the principles of autonomy and self-sufficiency, and thus underlines the primary status of innovation and progress, is widely shared by participants in the Chinese power and control discourse. The government has also started some action for consumer information and workplace safety, but without any significant outcome yet.

For researchers, the power and control discourse is mainly framed by reflections on scientists' responsibility to society. With the outbreak of a series of food safety scandals in recent years, however, there has been growing public concern about the negative implications of science and the social responsibility of scientists. Therefore some elite scientists have expressed views on the potential negative impact of nanotechnologies and recommended an increased public awareness of nanotechnologies.

Many issues that can be related to power and control discourse arose with the emergence of systematic and intensified ethical reflection in Chinese science communities from 2009. Besides advocating the participation of sociologists and humanists in nano research, elite scientists have called for self-regulation by the academic community and initiated the formulation of a code of conduct for nano research, which will be completed soon. These actions reflect the scientists' realization of their own social responsibility and their willingness to establish a more harmonious relationship between science and society-not least in order to foster and secure society's support for nanotechnological innovations. Some philosophers and social scientists have picked up the issues of social equity (the nanodivide) and of the consumer's right to make an informed choice. So far, however, there have been no systematic or in-depth discussions on the attribution of responsibilities among the state, enterprises and scientists in the management of nanotechnology or on the mechanism of accountability.

Overall, the power and control discourse in academia is centred on the value of harmony. Here harmony serves as an overarching or integral concept covering a wide range of other values and principles, including equity, justice, citizen's rights and freedom, non-maleficence and sustainability. By arranging these values and principles in a harmonious way, progress and affluence will be secured.

\subsubsection{India}

In India too, the nanotechnology power and control discourse is overshadowed by the government's innovation discourse, which harbours an optimistic vision of the application of nanotechnologies in addressing many societal challenges and furthering economic development. Therefore, as in China, many of those involved in the nanotechnology field hold the view that India should 'innovate now, regulate later'. Some experts do criticize the government, though, for particularly promoting research projects that lead to commercially viable and profitable products, while not giving enough support to those that focus on addressing societal needs and integrating different stakeholders' views. A few experts also call for more governmental activity to inform the public about the risks and benefits of 
nanotechnologies, as well as the introduction of a labelling system giving consumers the opportunity to make an informed choice. A significant difference between the Indian and the Chinese discourses on power and control is that criticism in India is directed at the government, which is held responsible for the governance of nanotechnologies-or its failure.

Power and control discussions in India seem to be driven by the principles of justice and autonomy. Justice is addressed by calls to ensure access, equity and inclusion concerning the benefits of nanotechnologies: nano-based products and services should be available and affordable for all. The principle of autonomy is invoked in calls for increased stakeholder involvement in nanotechnology policy framing, as well as in claims for product labelling to ensure consumer choice.

\subsection{Crosscutting Spheres of Lay Morality and Reflective Ethics}

Culturally embedded values play an important role in the construction of sociotechnical systems: they are the context in which the sociotechnical system of nanotechnology is situated in each region. Therefore an assessment of lay morality and of professional ethical considerations plays an important role in translating nanotechnology into a robust sociotechnical system. Ethical reflections can help to clarify the value-laden discussions and confusion around the acceptability of nanotechnologies, particularly by exposing and elucidating the (partly hidden) conflict lines, in order to allow substantive discussions. Even if ethical reflections cannot always provide solutions to value conflicts, they can at least structure argumentation lines and thus enable conflicting parties to enter a process of mutual learning and understanding as an important precursor to the discursive solution of conflicts arising within new sociotechnical systems.

Concerning the social robustness of nanotechnologies, it can be stated that nanotechnology has not (yet) become a big public issue provoking discussions and opinion-forming processes among citizens in the three regions. Studies on the media reporting of nanotechnologies suggest that there is no wide-ranging societal debate in any of the regions. Most newspaper articles on nanotechnology are formulated in a neutral and descriptive style.

\subsubsection{European Union}

Various more or less experimental public engagement projects and opinion assessment procedures have been carried out to assess public attitudes towards nanotechnologies in Europe and thus anticipate and assess the social robustness of nanotechnologies. A great deal of research into the translation of lay views into technology policy-making processes remains to be done, but the main issues of 
lay perception of nanotechnologies can be summarized as follows: Lay people acknowledge the potential benefits of nanotechnologies for human health and the environment, but, at the same time, express concerns about different aspects of nanotechnologies, like privacy, justice, market power, regulatory gaps, transparency and risk management.

Besides these experimental forms of technology assessment, the ethical assessment of nanotechnologies has been undertaken by several expert bodies and technology assessment institutions in Europe, along with scholars of science and technology studies from ethics, philosophy and the social sciences, as well as NGOs. The inclusion of ethical expertise in technology policy-making has become standard in European technology assessment methodologies. In the past 10 years the ethical debate on nanotechnologies has evolved, since it was characterized by the dispute between a dominant consequentialist approach and opposing deontological frameworks, into an opening up of the consequentialist framework of classical EHS risk assessment. The ethics discourse as such has also covered the other discourses and related value conflicts. Besides considerations of the precautionary principle as an instrument to deal with scientific and normative uncertainties, the broader issues of socioeconomic and cultural implications have been addressed. Several authors have emphasized the coevolution of science, technology and society. There has also been (meta-) reflection on the proper framework for ethical reflection on nanotechnologies. That development has been dominated by ethicists, philosophers and social scientists.

Throughout their strong engagement in the risk and the power and control debate, the NGOs have also made important contributions. The European Commission too has taken part in the reflective ethics discourse, for instance by funding ethical research projects and requesting an opinion on nanomedicine from the European Group on Ethics. At least with its code of conduct the commission took up ethical principles and values, but in quite a vague and non-binding manner.

\subsubsection{China}

Such institutionalized ethics debates and structures can be found in neither China nor India. But with the first academic meetings on the ethics of nanotechnologies in China, from 2009 onwards, structures of a genuine ethics discourse emerged within scientific circles, similar to and overlapping with the power and control discourse.

In China, moral and ethical reflections on nanotechnology can mainly be found in the academic circles of scholars on ethics and philosophy. From 2002, when discussion of the ethical issues of nanotechnology began, to 2008, a dozen papers were published on the ethical and social aspects of nanotechnology, mainly inspired by foreign research in the field. In 2009, when the first academic meeting focusing on the ethics of nanotechnology in China took place, the ethics 
discussion entered a new stage. The discussion of nanoethics mainly treats three aspects: ethical accountability, ethical consequences and ethical practices. Those ethics discussions are thematically crosscutting, in linking various aspects of nanotechnology to ethical considerations. But it is questionable whether the matter is crosscutting among actors in the nanotechnology field, especially concerning policy-makers and industry. This observation goes hand in hand with the low visibility of lay morality expressions, although there is an increasing perceived need-particularly among scientists, but also among policymakers-for lay opinion assessment in science policy. The media report on nanotechnologies from time to time, but in a distant and neutral manner.

\subsubsection{India}

For India, apparently, the moral and ethical assessment of nanotechnologies is not an important topic, although a qualitative study involving 120 practitioners from 21 laboratories across India (Patra et al. 2010) indicated that most of the Indian practitioners working in the field of nanoscience and nanotechnology research recognized ethical issues in this research area. These findings are supported by a recent survey among 35 nanoscientists in public funded research and development centres across India (Sahoo 2013). As in the risk discourse, there are certain Indian authors who are trying to get internationally discussed ethics issues higher up on Indian science and policy agendas (e.g. Radhakrishnan 2007).

\subsection{Conclusion: Governance, Discourses and Values}

This chapter's comparative analysis of nanodiscourses, nanopolicies and their underlying value concepts across three regions has revealed differences in the governance settings of technological innovation. These differences are, of course, strongly related to socioeconomic conditions, but are also influenced by dominant value concepts, which serve as focal points for ethical reflections on nanotechnology issues and are inherently part of the political core beliefs of policy-makers. When comparing the discourses of innovation, risk, and power and control, and their references to distinct cultural value concepts and principles, we can observe differences between the discourse structures in each region-that is, in the alignment of the discourses to each other.

In Europe, the proponents of the risk discourse as well as of the power and control discourse scrutinize or attack the innovation discourse and try to offer an alternative innovation path with a more critical and precautionary focus on risk issues and questions of power and control, thereby invoking the same European values, but with a different conception. Public authorities use a kind of incremental governance approach that recognizes critical issues and takes them up on the agenda 
if public pressure is anticipated-a lesson from the controversy around genetically modified organisms. An important point that distinguishes Europe from China and India is the early and strong involvement of science and industry stakeholders, together with stakeholders from civil society organizations and ethics experts, in nanotechnology policy formulation. Bringing all stakeholders and experts together allows creative solutions for innovative products to be found and market opportunities better anticipated. This is where the Chinese government in particular has a problem: China has large research capacities, but few spillovers from science into industry.

In China, the innovation discourse is the integral part of the nano discourse, in that it sets the framework for the subdiscourse of risk and that of power and control. On the value side, this goes hand in hand with a rather broad assumption of peace and harmony relating to issues of risk and power and control that promises progress and affluence for the Chinese nation. Therefore the Chinese governance style in nanotechnology development can be characterized as vertical and technocratic or scientistic. This also applies to ethics and moral issues, which are aligned to the innovation rationale and discussed in closed scientific circles. It is still an open question whether scientists, thanks to their high reputation and authority, are able to place critical issues touching on moral and ethical questions on the policy agenda.

In India, the innovation discourse is almost the only discourse on nanotechnologies. Nonetheless, some arguments are put forward against this strong innovation rationale, to the effect that it could undermine the values of access, equity and inclusion. Almost all government funding for nanotechnologies is spent on promising basic research and, most important, application-oriented research. Risk assessment is a minor activity that is at an early stage of development, since other societal challenges outweigh the perceived need for research on possible risks related to nanotechnologies. The Indian governance approach towards nanotechnologies can therefore be characterized as quite reductionist. This situation of rather weak risk governance is most likely due to the government's view that it is too early to decide on regulating a new and promising technology.

These different governance settings in each region are also distinct in the crosscutting spheres of ethics and lay morality: in China, there is an evolving genuine ethics discourse on nanotechnologies, with scientists reflecting on the relationship between science and society-something that has not yet happened in India. But these reflections by Chinese researchers have not yet reached policy circles or the stage of institutionalization. In Europe, there are several institutionalized forms of ethical expertise, as well as civil society organizations and others, situated in the spheres between lay morality and professional ethics. They form a kind of background to discussions and discourses on nanotechnology development, and the development of further technologies. Some researchers are even trying to explore and deepen our understanding of lay morality and its cultural embeddedness in European member states or regions, whereas in China and India, the integration of forms of lay morality into nanotechnology development policy seems hardly present yet. 
Open Access This chapter is distributed under the terms of the Creative Commons Attribution Noncommercial License, which permits any noncommercial use, distribution, and reproduction in any medium, provided the original author(s) and source are credited.

\section{References}

Aguar P, Murcia Nicolas JJ (2008) EU nanotechnology R\&D in the field of health and environmental impact of nanoparticles. European Commission. ftp://ftp.cordis.europa.eu/pub/nanotechnology/docs/final-version.pdf. Accessed 19 June 2014

CIEL et al (2011) NGO recommendations for the European definition of nanomaterials. Centre for International Environmental Law, Geneva; European Environmental Bureau, Brussels

Dhawan A, Sharma V (2011) Address risk of nanotech toxicity. SciDevNet. http://www.scidev.net/ global/technology/opinion/address-risk-of-nanotech-toxicity-1.html. Accessed 19 June 2014

DST (2001) Annual report 2000-2001. Department of Science and Technology, Government of India

DST (2008) Annual Report 2007-2008. Department of Science and Technology, Government of India

European Commission (2004) Towards a European strategy for nanotechnology. Office for Official Publications of the European Communities, Luxembourg

European Commission (2005) Nanosciences and nanotechnologies: an action plan for Europe 2005-2009. Office for Official Publications of the European Communities, Luxembourg

European Commission (2008) Commission recommendation of 07/02/2008 on a code of conduct for responsible nanosciences and nanotechnologies research. Commission of the European Communities, Brussels

Fautz C (2013) Ethics debates on nanotechnologies in the EU. Global Ethics in Science and Technology (GEST), Deliverable 3.1

Fautz C, Ma Y, Liao M, Kumar A (2014) Ethics debates on nanotechnologies in the EU, China and India. Global Ethics in Science and Technology (GEST), Deliverable 3.2

Grunwald A (2005) Vision assessment as a new element of the FTA toolbox. In: Scapolo F, Cahill E (eds) New horizons and challenges for future-oriented technology analysis. Proceedings of the EU-US scientific seminar: new technology foresight, forecasting and assessment methods. Institute for Prospective Technological Studies, Joint Research Centre (DG JRC), European Commission

Hett A (2004) Nanotechnology: small matter, many unknowns. Swiss Reinsurance Company, Zurich

Kurath M, Maasen S (2006) Toxicology as a nanoscience? Disciplinary identities reconsidered. Part Fibre Toxicol 3:6

Lauterwasser C (ed) (2005) Small sizes that matter: opportunities and risks of nanotechnologies. Report in co-operation with the OECD International Futures Programme. Allianz AG, Munich, OECD International Futures Programme, Paris

Malsch I (ed) (2004) 4th Nanoforum report: benefits, risks, ethical, legal, and social aspects of nanotechnology. http://www.nanowerk.com/nanotechnology/reports/reportpdf/report3.pdf. Accessed 19 June 2014

MOST (2001) National programme on the development of nanoscience and nanotechnology(2001-2010). Ministry of Science and Technology of the People's Republic of China. http://www.most.gov.cn/fggw/zfwj/zfwj2001/200512/t20051214_55037.htm. Accessed 19 June 2014

MOST (2006) Outline of national medium- and long-term science and technology development plan (2006-2020). Ministry of Science and Technology of the People's Republic of China. http://www.most.gov.cn/kjgh/kjghzcq/. Accessed 19 June 2014

MOST (2012a) The 12th five-year national plan for science and technology development. Ministry of Science and Technology of the People's Republic of China. http://www.most.gov. $\mathrm{cn} / \mathrm{kjgh} /$ sewkjfzgh/. Accessed 19 June 2014

MOST (2012b) The 12th five-year special plan for major national scientific research program on nano research. Ministry of Science and Technology of the People's Republic of China. http://www.most.gov.cn/tztg/201206/W020120621519855469640.doc. Accessed 19 June 2014 
National Science and Technology Council (2000) National nanotechnology initiative: the initiative and its implementation plan. Subcommittee on Nanoscale Science, Engineering and Technology, Committee on Technology, National Science and Technology Council, Washington DC

Patra D, Haribabu E, McComas KA (2010) Perceptions of nano ethics among practitioners in a developing country: a case of india. Nanoethics 4(1):67-75

Pradeep T, Burgi BR (2006) Societal implications of nanoscience and nanotechnology in developing countries. Curr Sci 90(5):645-658

Radhakrishnan G (2007) Other side of nanotech. The Hindu, 18 March

Ren H, Zhang D (2010) Explore the mode of industrialization of nanotechnology (in Mandarin). Adv Mater Ind 11:78-81

Roco M. (2007) National nanotechnology initiative: past, present, and future. In: Goddard WA, Brenner DW, Lyshevski SE, Iafrate GJ (eds) Handbook of nanoscience, engineering, and technology, 2nd edn, pp 16-26. CRC Press, Taylor \& Francis Group, Boca Raton FL

Sahoo S (2013) Would you mind, if we record this? Perceptions on regulation and responsibility among Indian nanoscientists. Nanoethics 7:231-249

Schummer J (2007) The global institutionalization of nanotechnology research: a bibliometric approach to the assessment of science policy. Scientometrics 70:669-692

Seetharam RN, Sridhar KR (2007) Nanotoxicity: threat posed by nanoparticles. Curr Sci 93(6):769-770

Shen D, Wang X (2011) The process of standardization of nanotechnology and related ethical issues. Chin Sci Bull 56(2):131-134

Srinivasan C (2008) Toxicity of carbon nanotubes: Some recent studies. Curr Sci 95(3):307-308

Wullweber J (2010) Hegemonie, Diskurs und politische Ökonomie: Das NanotechnologieProjekt. Nomos, Baden-Baden

Zhao Y, Chai Z (2005) Status of study of bio-environmental activities of nanoscale materials. Bull Chin Acad Sci 20(3):194-199

Zhou L (2007) Governing China's local officials: an analysis of promotion tournament model. Econ Res J 7:36-50 